
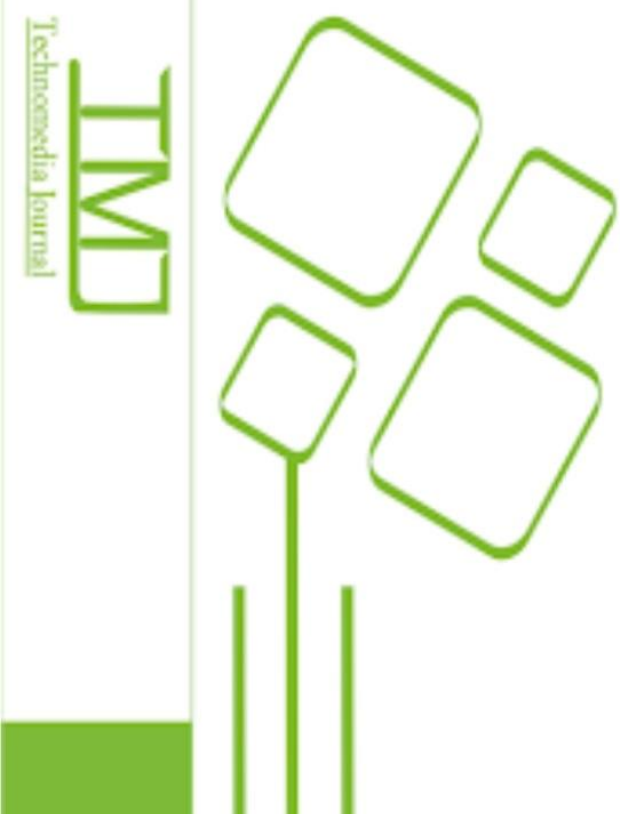

E-ISSN: $2528-6544$

P-ISSN: 2620 - 3383

Vol.1 No.1 Agustus 2016

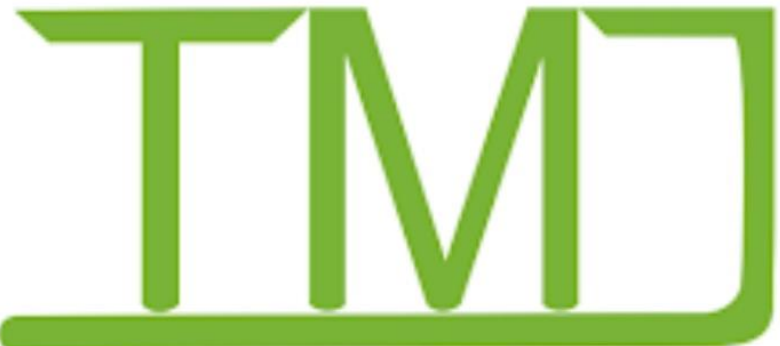

Technomedia Journal

iLearning Journal Center (iJC)

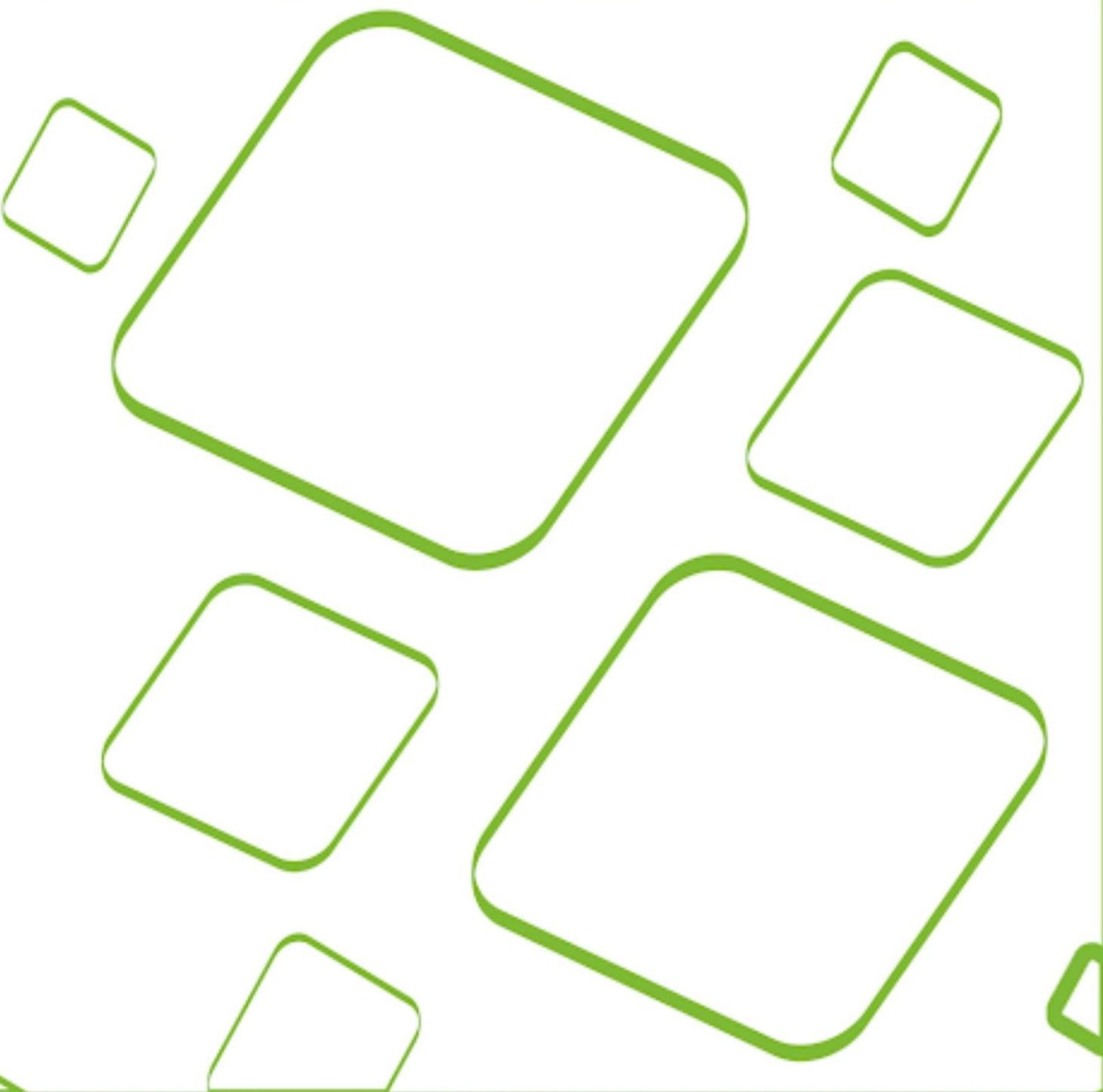


Technomedia Journal adalah jurnal elektronik ilmiah yang diterbitkan oleh iJC (iLearning Journal Center). Technomedia Journal terbit tiga kali dalam satu tahun Februari, Juni, dan Oktober yang berisi artikel hasil penelitian dalam bidang Sistem Informasi dan Teknologi Informatika.

\section{Ketua Redaksi :}

Ir. Untung Rahardja.,M.T.I

\section{Sekretaris Redaksi :}

Indri Handayani, S.Kom., M.T.I

\section{Mitra Bestari :}

Prof. Ir. Joko Lianto Buliali, M.Sc.,Ph.D

Prof. Dr.rer.nat. Achmad Benny Mutiara, SSi, SKom

Prof. Dr. Moedjiono. MSc

Dr. Winarno

Dr. Harco Lesly

Panca Oktavia Hadi Putra, Bsc., M.Sc.,

Henderi, M.Kom

Dr. Ir. I. Joko Dewanto, MM

Dr. Ir. Sudatyono, S.Pd., M.Pd

\section{Editor/ Layout : \\ Maulana Sani \\ Yuli Widiastuti}

\section{Bendahara:}

Eka Purnama Harahap, S.Kom

\section{Alamat Redaksi :}

Jl. Jendral Sudirman No 40, Cikokol - Tangerang Tel / fax : (021)5529692

Email: ijc@ raharjagroups.info atau ijc@ raharja.info 


\section{Dewan Redaksi}

Puji dan syukur kehadirat Allah SWT atas karunia dan lindunganNya sehingga TMJ terbitan Vulume 1 Nomor 1 Edisi Oktober 2016 dapat diterbitkan tepat waktu.

Penerbitan jurnal ini dimaksudkan sebagai media informasi ilmiah dibidang ilmu komputer yang diharapkan dapat membantu para dosen dan mahasiswa dalam menginformasikan hasil penelitian dan kajian ilmiah lainnya kepada berbagai komunitas ilmiah diseluruh Indonesia.

Penerbitan jurnal Volume 1 Nomor 1 Edisi Oktober 2016 berisikan 10 artikel yang mencakup bidang Ilmu Komputer, Teknologi Informasi, Sistem Informasi, walaupun tidak seluruhnya merupakan hasil penelitian diharapkan dapat bermanfaat bagi pembacanya. Puji syukur kehadirat Allah SWT karena 10 artikel adalah dari STMIK dan AMIK Raharja.

Jurnal ini diterbitkan dengan memuat artikel Fitur Form Emailer Dalam Memaksimalkan Penggunaan Rinfo Form Pada Perguruan Tinggi, Implementasi Fgr (First Generation Resources) Dengan Menggunakan Mailchimp Sebagai Sarana Informasi Di Perguruan Tinggi, Optimalisasi Penerapan Rooster Berbasis Osticket Untuk Meningkatkan Mutu Pelayanan, Penerapan Rinfosheet Sebagai Media Penunjang Pembuatan Laporan Untuk Mahasiswa, Penerapan Rinfosheet Sebagai Media Penunjang Pembuatan Laporan Untuk Mahasiswa, Optimalisasi Viewboard Rhjfox Berbasis Bootstrap Sebagai Sistem Penunjang Keputusan, Penerapan Viewboard Go+ Berbasis Yii Sebagai Media Monitoring Pembayaran Mahasiswa, Pemanfaatan Rinfo Form Sebagai Media Pembuatan Kuesioner Dalam Proses Pengumpulan Data Pada Perguruan Tinggi, Pemanfaatan Google Scholar Dan Citation Dalam Memenuhi Kebutuhan Pembuatan Skripsi Mahasiswa Pada Perguruan Tinggi, Penerapan Mata Uang Armo (Airzone-Mall Money) Pada Marketplace Airzone-Mall Sebagai Inovasi Pembelajaran Internet Dan E-Commerce, Media Audio Visual Menggunakan Videoscribe Sebagai Penyajian Informasi Pembelajaran Pada Kelas Sistem Operasi.

Tidak lupa pula pada kesempatan ini kami mengundang para pembaca untuk mengirimkan naskah hasil penelitian kepada kami. Dan tidak lupa pula kami mengucapkan banyak terimakasih kepada semua pihak yang telah membantu penerbitan jurnal ini.

Tangerang, 31 Oktober 2016

Redaksi 


\section{Daftar Isi}

1. FITUR FORM EMAILER DALAM MEMAKSIMALKAN PENGGUNAAN RINFO FORM PADA PERGURUAN

TINGGI.......................

2. IMPLEMENTASI FGR (FIRST GENERATION RESOURCES) DENGAN MENGGUNAKAN MAILCHIMP SEBAGAI SARANA INFORMASI DI PERGURUAN TINGGI Qurotul Aini, Indri Handayani, Nuril Huda

3. OPTIMALISASI PENERAPAN ROOSTER BERBASIS OSTICKET UNTUK MENINGKATKAN MUTU PELAYANAN

4. PENERAPAN RINFOSHEET SEBAGAI MEDIA PENUNJANG PEMBUATAN LAPORAN UNTUK MAHASISWA

Khanna Tiara Erlita Rasdiana, Nursam Somantri

5. OPTIMALISASI VIEWBOARD RHJFOX BERBASIS BOOTSTRAP SEBAGAI SISTEM PENUNJANG KEPUTUSAN...... 50-64 Untung Rahardja, Khanna Tiara, Maya Ima Erviani

6. PENERAPAN VIEWBOARD GO+ BERBASIS YII SEBAGAI MEDIA MONITORING PEMBAYARAN MAHASISWA Khanna Tiara Tuti Nurhaeni, Ika amalia

7. PEMANFAATAN RINFO FORM SEBAGAI MEDIA PEMBUATAN KUESIONER DALAM PROSES PENGUMPULAN

DATA PADA PERGURUAN TINGGI

Erlita Rasdiana, Fadil Nur Muhamad, Ridwan Kurniaji

8. PEMANFAATAN GOOGLE SCHOLAR DAN CITATION DALAM MEMENUHI KEBUTUHAN PEMBUATAN SKRIPSI MAHASISWA PADA PERGURUAN TINGGI..................... Untung Rahardja, Khanna Tiara, Iis Ariska Rosalinda

9. PENERAPAN MATA UANG ARMO (AIRZONE-MALL MONEY) PADA MARKETPLACE AIRZONE-MALL SEBAGAI INOVASI PEMBELAJARAN INTERNET DAN E-COMMERCE. Qurotul Aini, Untung Rahardja, Dita Lintang Nurani

10. MEDIA AUDIO VISUAL MENGGUNAKAN VIDEOSCRIBE SEBAGAI PENYAJIAN INFORMASI PEMBELAJARAN PADA KELAS SISTEM OPERASI 


\title{
Optimalisasi Penerapan Rooster Berbasis Osticket Untuk Meningkatkan Mutu Pelayanan
}

\author{
Untung Rahardja 1 \\ Khanna Tiara ${ }^{2}$ \\ Ria Utami ${ }^{3}$ \\ Jl. Jend. Sudirman No. 40, Modern Cikokol, Tangerang ${ }^{1,2,3}$ \\ E-mail : untung@raharja.info ${ }^{1}$, khanna.tiara@ raharja.info² ${ }^{2}$ ria.utami@ raharja.info ${ }^{3}$
}

\begin{abstract}
ABSTRAK
Dalam sebuah Perguruan Tinggi, penyediaan suatu pelayanan informasi sangatlah penting apalagi jika didukung dengan kecanggihan teknologi yang kian berkembang sangat pesat. Perguruan Tinggi Raharja merupakan salah satu kampus yang bergerak dibidang IT yang memiliki sebuah sarana atau media dalam hal pelayanan informasi kepada seluruh Pribadi Raharja yang merupakan bagian dan masih berkesinambungan didalam sebuah pelayanan lainnya yaitu iDuHelp!. Pelayanan informasi tersebut dinamakan ROOSTER (Role Online System Ticketing Raharja) yang fungsinya yaitu memberikan sebuah pelayanan berupa penyampaian informasi didalam sebuah tiket online yang dibuat oleh operator iDuHelp! dan tiket tersebut diberikan kepada customer iDuHelp! untuk mendapatkan pelayanan terusan yang akan ditindaklanjuti kepada pihak yang terkait yang disebut PIC atau admin dari masing-masing TPi dan FiR yang ada pada Perguruan Tinggi Raharja. ROOSTER merupakan sistem yang sudah berjalan cukup lama dari generasi ke generasi dan terus melakukan pengembangan serta perbaikan agar sistem tersebut dapat digunakan lebih optimal lagi, tujuan ROOSTER itu sendiri yaitu agar seseorang atau customer mendapatkan informasi yang akurat dari pihak yang terpercaya serta tersampaikan dengan tepat waktu. Terdapat beberapa kendala dalam sistem ROOSTER yang berjalan saat ini, seperti tiket overdue yang tidak pernah tampil lagi, ketidakakuratan sebuah data yang membuat tiket dengan full name yang tampil membuat pengguna ROOSTER tidak nyaman dan keliru dan informasi kerap kali terlambat diterima oleh customer, sehing ga dibutuhkannya suatu perbaikan agar performa ROOSTER dapat berjalan lebih baik lagi dan nyaman digunakan.
\end{abstract}

Kata kunci : ROOSTER, Pelayanan Informasi, iDuHelp!

\begin{abstract}
In a university, providing an information service is important especially if backed up with increasingly sophisticated technology is developing very rapidly. Prog College is one of the campus engaged in IT who have a medium or media in terms of information services to the whole person Prog that is part and still continuous in a more services are iDuHelp !. The information ministry called ROOSTER(Role Online Ticketing System Prog) whose function is to give a service in the form of information delivery in an online ticket made by the operator iDuHelp! and the ticket is given to the customer iDuHelp! to obtain the services of the canal will be followed to the relevant parties called PIC or administrator of each TPI and FIR contained in Higher Education Prog. ROOSTER is a system that has been running for a long time from generation to generation and continue to develop as well as improvements to the system can be used more optimally, the purpose ROOSTER itself, namely that persons or customers get accurate information from reputable parties and delivered in a timely manner. There are some constraints in the system ROOSTER currently running, such as ticket overdue that never appear again, inaccuracy of a data to create a ticket with a full name that appears to make the user ROOSTER uncomfortable and wrong and the information is often too late accepted
\end{abstract}

20 | Untung, Khanna, Ria-Optimalisasi Penerapan Rooster... 
by the customer, so it needs a ROOSTER performance improvements that can be run better and convenient to use.

Keywords : ROOSTER, Information Services, iDuHelp!

\section{PENDAHULUAN}

Seiring dengan perkembangan teknologi yang terus berkembang dengan begitu pesat, memacu Perguruan Tinggi Raharja untuk ikut serta dalam meningkatkan kualitasnya khususnya dibidang IT (Information Technology) salah satunya untuk dapat memenuhi kebutuhan serta memberikan pelayanan yang terbaik kepada seluruh civitas akademika yang ada pada Perguruan Tinggi Raharja, selain untuk meningkatkan kualitas Perguruan Tinggi itu sendiri dengan adanya pelengkap fasilitas pelayanan kampus yang akan digunakan oleh banyak orang khususnya para staff, dosen dan juga mahasiswa, sehingga manfaat akan banyak dirasakan tidak hanya untuk kampus melainkan juga untuk semua Pribadi Raharja yang biasanya mahasiswa laksanakan dalam bentuk tri dharma.

Perguruan Tinggi Raharja memiliki sebuah sistem pelayanan kampus yang bernama iDuHelp!. iDuHelp! merupakan sistem pelayanan kampus dimana pelayanan ini terdapat dua pelayanan yaitu onsite dan offsite. Pelayanan iDuHelp! diperuntukkan melayani pertanyaanpertanyaan yang diajukan oleh mahasiswa dan dosen dan harus berdasarkan ruang lingkup iDuHelp! yang ada pada seputar TPi (Ten Pilar IT Learning) dan FiR (Future IT Raharja) seperti 10 TPi yang dimiliki oleh Perguruan Tinggi Raharja yaitu iMe, Rinfo, Widuri, iSur, iDu, iRan, ROOSTER, iDuHelp!, Magics Channel dan iRme, serta memiliki 23 FiR yang ada pada Perguruan Tinggi Raharja. Di dalam sebuah pelayanan iDuHelp!, beberapa pertanyaan tertentu dari customer diharuskan menggunakan sebuah ticket online yang akan ditujukan kepada pihak atau admin yang terkait yang dinamakan tiket ROOSTER (Role Online System Ticketing Raharja) yang merupakan bagian dari sistem pelayanan pada iDuHelp! yaitu penyampaian suatu informasi kepada pihak yang terkait melalui sebuah tiket yang disampaikan oleh operator iDuHelp! agar mendapatkan sebuah jawaban yang akurat dan terpercaya yang akan disampaikan kembali kepada customer. Informasi adalah data yang sudah diolah menjadi sebuah bentuk yang berguna bagi pengguna yang bermanfaat dalam pengambilan keputusan saat ini atau mendukung sumber informasi ([Menurut Kusrini 2007]) ROOSTER juga bisa diartikan sebagai media untuk memberikan informasi dengan cara operator memberikan sebuah tiket ROOSTER kepada customer dan tiket tersebut ditujukan kepada PIC terkait, karena yang bisa menjawab dan mengeksekusi pertanyaan yang diajukan hanyalah PIC atau admin yang terkait, kemudian operator tersebut membuatkan tiket ROOSTER kepada PIC atau admin yang terkait untuk dimintai jawaban yang akurat untuk dapat disampaikan kepada customer dalam waktu 2x24 jam penanganan tiket ROOSTER tersebut. Pelayanan adalah setiap tindakan atau kegiatan yang dapat ditawarkan oleh suatu pihak kepada pihak lain, yang pada dasarnya tidak berwujud dan tidak mengakibatkan kepemilikian apapun ${ }^{\text {([Menurut Kotler 2002]) }}$

ROOSTER merupakan sistem yang digunakan dan berjalan hampir setiap harinya yang dibutuhkan oleh para customer baik dosen maupun mahasiswa yang telah menghubungi iDuHelp!. Saat ini sudah terdapat 132 tiket ROOSTER yang masuk dan terlayani, ROOSTER memiliki 183 staff ROOSTER yang diantaranya 103 staff berstatus active dan 80 berstatus locked. Untuk membantu jalannya Tri Dharma iDuHelp!, terdapat banyak artikel di dalam 
iRan yang berkaitan dengan ROOSTER yaitu sebanyak 20 artikel dengan total pengunjung lebih dari 100 pengunjung didalamnya. Sistem yang berjalan saat ini terdapat beberapa kendala serta kekurangan yang dinilai masih kurang efektif dan dibutuhkannya suatu perbaikan pada sistem untuk dapat mengoptimalkan jalannya sistem yang berjalan saat ini agar dapat memenuhi kebutuhan serta kepuasan dan kenyamanan untuk para customer iDuHelp!. Kepuasan adalah perasaan senang atau kecewa seseorang yang muncul setelah membandingkan antara persepsi atau kesan terhadap kinerja atau hasil suatu produk dan harapan-harapannya ${ }^{([M e n u r u t ~ K o t l e r ~ 2012]) ~}$.

Permasalahan dalam sistem ROOSTER yang sedang berjalan saat ini adalah sulitnya admin atau PIC mengetahui siapa yang sebenarnya membuatkan tiket untuknya dikarenakan email operator yang diinputkan hasilnya tidak sama dengan full name yang muncul pada halaman depan open ticket. Hal ini sering kali membuat PIC dan operator tidak nyaman dalam menggunakan sistem ROOSTER karena adanya data yang tidak sesuai dan lagi dalam hal penyampaian informasi kepada customer sering sekali operator lalai atau lupa dalam menyelesaikan kewajibannya sampai menyampaikan informasi kepada customer melalu email iDuHelp!. Diharapkan dengan adanya perbaikan pada sistem ROOSTER dapat memberikan kemudahan dan pengoptimalan cara kerja sistem untuk dapat memudahkan serta memberikan kenyamanan bagi para pengguna ROOSTER.

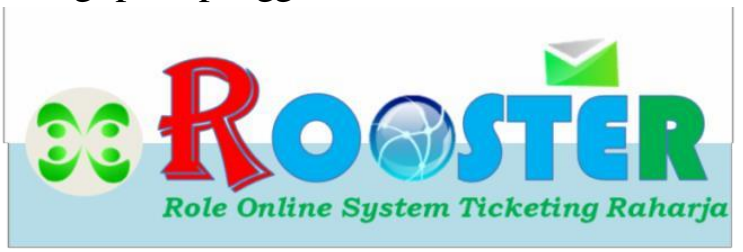

Sumber: Logo ROOSTER (2016: rooster.ilearning.me)

Gambar 1. Logo ROOSTER (Role Online System Ticketing Raharja)

\section{PERMASALAHAN}

ROOSTER merupakan bagian dari pelayanan iDuHelp! yang ada pada Perguruan Tinggi Raharja yang tujuannya adalah memberikan sebuah informasi yang akurat, terpercaya, dan tepat waktu. Penggunaan sebuah sistem yang nyamanpun sangat mempengaruhi kinerja dari staff ROOSTER dalam menjalankan pekerjaannya sebagai operator iDuHelp! dengan baik. Sistem yang berjalan saat ini terdapat beberapa problem serta kendala dan sistem ROOSTER ini merupakan sistem yang digunakan setiap harinya di Perguruan Tinggi Raharja dikarenakan ROOSTER merupakan bagian dari sistem pelayanan kampus yang ada pada proses chatting iDuHelp! online dan offline. Cara penyampaian informasi yang akurat kepada customer pun sering kali terbengkalai karena lupa ataupun mengabaikannya. Hal ini sering sekali membuat customer tidak puas ataupun complain perihal tersebut, serta para pengguna seperti operator dan PIC pun merasa tidak nyaman karena adanya ketidaksesuaian data yang dimasukkan dengan tampilan yang muncul. Maka diperlukannya sebuah perbaikan pada sistem ROOSTER tersebut untuk dapat meminimalisir kekeliruan akibat ketidaksamaan data serta diperlukannya suatu metode atau cara untuk dapat memudahkan para operator menyampaikan informasi yang akurat kepada customer dengan tepat waktu sesuai prosedur ROOSTER yang berlaku dalam penanganan tiket ROOSTER yaitu $2 \times 24$ jam. 
Prosedur yang berjalan pada sistem ROOSTER saat ini yaitu customer melakukan chatting online atau offline pada iDuHelp! kemudian operator tersebut menangani untuk pertanyaan tertentu dengan memberikan sebuah tiket ROOSTER dengan 4 digit angka kepada customer dan customer bisa melakukan cek pada Viewboard ROOSTER untuk melihat status informasi bahwa tiket tersebut telah dibuatkan dan jika sudah ditangani maka akan berstatus closed. Tiket ROOSTER ditujukan kepada PIC yang terkait untuk dapat mengeksekusi permasalahan yang terjadi dan akan segera diberikan jawaban yang akurat oleh PIC yang terkait kepada operator untuk disampaikan kepada customer. Dalam pembuatan tiket ROOSTER saat ini, operator input email Rinfonya yang terjadi pada tampilan full name yang keluar adalah nama orang lain dan ini dinilai sangat tidak nyaman dan bukan hal yang dinilai bagus dalam suatu sistem.

\begin{tabular}{|l|l|}
\hline Open New Ticket & \\
\hline New Ticket & \\
\hline User Information & \\
\hline Email Address: & Ria.utami@raharja.info \\
\hline Full Name: & Lia Suci Wulandari \\
\hline
\end{tabular}

Sumber : Tampilan full name pada sistem (rooster.raharja.info)

Gambar 2. Tampilan Full Name Tidak Sesuai Dengan Email Yang diinputkan

Kekeliruan data yang masuk bukan dari nama yang sebagai pembuat tiket sebenarnya akan membingungkan seseorang untuk dapat mengetahui informasi sebenarnya karena data tersebut tidak akurat, baiknya sebuah sistem yang baik adalah memiliki data yang akurat dan mudah dipahami oleh para penggunanya. Maka dari permasalahan yang terjadi sangat dibutuhkan cara untuk dapat memperbaiki sistem ROOSTER yang ada menjadi lebih baik agar dapat dijalankan secara optimal, selain itu juga memberikan kenyamanan kepada pengguna dengan memberikan kemudahan untuk dapat menyampaikan informasi yang akurat dari media atau sistem yang telah disediakan.

Pada sebuah penamaan dalam assign to juga dinilai masih kurang optimal karena masih sulit dicari dari urutan nama, assign to adalah dimana tiket tersebut akan ditujukan untuk dimintai jawabannya atas pertanyaan yang ada pada chatting iDuHelp!. Dilihat bahwa dari sistem yang berjalan pada ROOSTER yaitu urutan nama pada assign to dari nama belakang, kemudian nama depan sehingga operator harus mengetahui nama lengkap terutama nama belakang dari PIC tersebut, hal ini dinilai kurang bagus, tidak memudahkan operator dalam melakukan tugasnya sebagai operator iDuHelp!.

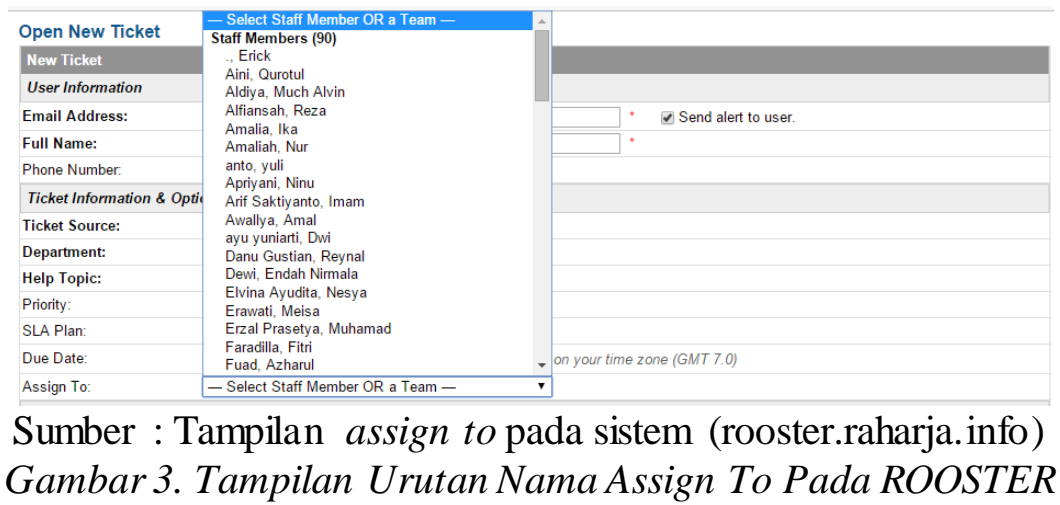


Maka dari permasalahan yang telah dijabarkan diatas, rumusan masalah dalam penelitian ini adalah bagaimana menciptakan sebuah sistem pelayanan informasi yang mampu memberikan kenyamanan kepada pengguna dan tersampaikan dengan tepat waktu. Berdasarkan rumusan masalah yang telah di identifikasi maka hasil yang diharapkan adalah menciptakan sebuah sistem yang mampu memudahkan dan memberi kenyamanan kepada pengguna serta membantu customer dalam menerima informasi yang akurat dengan tepat waktu, dan meningkatkan kualitas mutu pelayanan informasi pada Perguruan Tinggi Raharja.

\section{LITERATURE REVIEW}

Literature review adalah bahan yang tertulis berupa buku, jurnal yang membahas tentang topik yang hendak diteliti $\left.\left.{ }^{([M e n u r u t ~ H e r m a w a n ~} 2010\right]\right)$. Sebelumnya banyak penelitian yang dilakukan mengenai sistem pelayanan informasi pada Perguruan Tinggi. Dalam upaya memperbaiki suatu sistem pelayanan informasi yang sedang berjalan pada Perguruan Tinggi Raharja saat ini diperlukan suatu studi pustaka sebagai salah satu penerapan metode yang akan dilakukan. Berikut ini adalah 10 (sepuluh) penelitian yang telah dilakukan serta memiliki kolerasi yang searah dengan penelitian yang akan dibahas dalam jurnal, diantaranya yaitu :

1. Penelitian yang dilakukan oleh Untung Rahardja, Dewi Immaniar Desrianti, Ayu Wanda Lestari pada tahun 2014 penelitian ini berjudul "Kepuasan Pelanggan ROOSTER Atas Kinerja Pelayanan ROOSTER Pada Perguruan Tinggi Raharja”. Pada penelitian ini membahas tentang tingkat kepuasan dari kinerja pelayanan ROOSTER yang dilakukan dengan cara pengumpulan data dari hasil penyebaran kuesioner online dengan menggunakan iSur kepada customer yang menggunakan tiket ROOSTER.

2. Penelitian yang dilakukan oleh Untung Rahardja, Nur Azizah, Santika Dewi pada tahun 2013 penelitian ini berjudul "Sistem Pelayanan Dukungan Role Online System Ticketing Raharja (ROOSTER) Dengan Menggunakan E-Ticket". Pada penelitian ini membahas tentang pembuatan sebuah aplikasi sistem pelayanan dukungan yang tepat dan akurat yaitu ROOSTER yang merupakan sebuah aplikasi sistem pelayanan dukungan berbasis online yang sangat praktis dengan metode sistem berbasis online.

3. Penelitian yang dilakukan oleh Untung Rahardja, Meta Amalya Dewi, Siti Rahmawati pada tahun 2014 penelitian ini berjudul "Penggunaan Ekstension Waktu Dalam Role Online System Ticketing Raharja (ROOSTER) Sebagai Penunjang Pelayanan iDuHelp!”. Pada penelitian ini membahas tentang masalah pelayanan yang terabaikan karena kurangnya waktu pada pelayanannya dengan pemecahan masalahnya yaitu dengan cara adanya sebuah sistem penambahan waktu dalam pelayanan jika dibutuhkan maka perbaikan sistem di ROOSTER pada kegiatan iDuHelp! di ROOSTER dapat berjalan dengan baik.

4. Penelitian ini dilakukan oleh Farah Virnawati dan Tirta Paramitta dari Universitas Gunadarma, Indonesia, pada tahun 2007 yang berjudul "Optimalisasi Penentuan Keputusan Ticketing Online Bagi Customer". Penelitian ini membahas proses transaksi yang sebelumnya dilakukan masih dengan cara yang konvensional diubah menjadi sebuah proses transaksi yang dilakukan berbasis online. Dampaknya yaitu semakin banyak kemudahan yang ditawarkan oleh berbagai produsen untuk dapat menarik customer. Penentuan keputusan yang diberikan oleh sistem pun harus benar-benar mewakili keinginan customer atau paling tidak mendekati dengan persyaratan yang diinginkan 
customer. Oleh karena itu, semakin banyak kemudahan-kemudahan yang ditawarkan oleh berbagai produsen untuk menarik customer, dengan memanfaatkan teknologi yang ada pada era ini.

5. Penelitian ini dilakukan oleh Winda Septianita, Wahyu Agus Winarno, dan Alfi Arif pada tahun 2014 yang berjudul "Pengaruh Kualitas Sistem, Kualitas Informasi, Kualitas Pelayanan Rail Ticketing System (RTS) Terhadap Kepuasan Pengguna (Studi Empiris Pada PT. Kereta Api Indonesia (PERSERO) DAOP 9 JEMBER)”. Tujuan Penelitian ini adalah untuk menguji pengaruh kualitas sistem, kualitas informasi serta kualitas pelayanan Rail Ticketing System (RTS) pada kepuasan pengguna. Penelitian ini menggunakan metode kuesioner dan wawancara dalam memperoleh data dan informasi untuk dianalisis.

6. Penelitian yang dilakukan oleh Untung Rahardja, Sunar Abdul Wahid, dan Nia Haryani pada tahun 2009 yang berjudul "Analisis Kinerja Student Information Services Menggunakan Technology Acceptance Model (TAM)”. Dalam penelitian ini membahas tentang analisa keoptimalan sebuah sistem pelayanan untuk ditindaklanjuti kekurangan sistem tersebut agar dapat menghasilkan sistem pelayanan yang lebih optimal dan dapat meningkatkan kepuasan user. Dalam hal ini Technology Acceptance Model lebih banyak digunakan. Metode ini membuat model tentang bagaimana pengguna mau menerima dan menggunakan teknologi. Penerapan model TAM kedalam analisa Student Information Services ditujukan untuk mengetahui sejauh mana kualitas pelayanan serta keoptimalan dari Student Information Services tersebut.

7. Penelitian ini dilakukan oleh Ainin Sulaiman dari University of Malaya, Faculty of Business and Accountancy, Kuala Lumpur, Malaysia, pada tahun 2008 yang berjudul " $E$ ticketing as a New Way of Buying Tickets : Malaysian Perceptions". Penelitian ini menjelaskan tentang mengidentifikasi e-ticketing trend di kalangan masyarakat perkotaan khususnya di Kuala Lumpur. Mengkaji trend penggunaan dan pola e-ticketing. Selain itu, juga berfokus pada perspektif pelanggan menuju e-ticketing dalam hal, kehandalan kegunaannya, keamanan, kenyamanan dan efisiensi. Penelitian ini juga menguji dampak dari variabel-variabel demografi pada e-ticketing adopsi terhadap e-ticketing. Penelitian ini menemukan bahwa kenyamanan dan kemudahan penggunaan adalah salah satu faktor yang memotivasi responden untuk membeli tiket online.

8. Penelitian ini dilakukan oleh Mazen Kamal Qteishat, Haitham Hmoud Alshibly, dan Mohammad Atwah Al-ma'aitah dari Albalqa Applied University, Amman, Jordan, pada tahun 2014 yang berjudul "The Impact Of E-Ticketing Technique On Customer Satisfaction : An Empirical Analysis". Penelitian ini menjelaskan tentang pengembangan dengan metode baru untuk berinteraksi dengan pelanggan dengan menggunakan e-ticket, yang bertujuan agar mempermudah proses transaksi dan memperkuat hubungan antara perusahaan dan pelanggan. Penelitian ini secara empiris mengkaji dampak dari teknik $e$ ticketing pada kepuasan pelanggan dan menunjukkan bahwa kepuasan pelanggan dengan layanan e-ticketing dipengaruhi oleh semua variabel independen diukur (keamanan data, pelanggan dan dukungan teknis, dan user-keramahan) yang tercatat memiliki dampak yang signifikan pada kepuasan pelanggan dengan layanan e-ticketing.

9. Penelitian yang dilakukan oleh Cagla Ozen Seneler, Nuri Basoglu, dan Tugrul U. Daim, dari University of York, York Inggris, pada tahun 2010 yang berjudul "An empirical 
analysis of the antecedents of adoption of online services: A prototype-based framework". Penelitian ini dimaksudkan untuk memperluas teori adopsi teknologi dengan mengintegrasikan mereka dengan orang-orang menjelajahi inovasi layanan dan upaya untuk mengeksplorasi faktor-faktor yang membantu atau menghalangi sikap terhadap menggunakan layanan online. Dengan demikian, penelitian ini bertujuan untuk memberikan wawasan tentang atribut yang pengembang dan desainer dari layanan tersebut harus memperhatikan. Studi ini menyelesaikan tujuan di atas melalui pengujian kerangka kerja yang dikembangkan sebagai hasil dari literature review, wawancara dan kelompok ahli yang terfokus serta survei. Satu set prototipe dikembangkan sebagai antarmuka alternatif untuk layanan online. Ada peningkatan minat dalam desain dan pengembangan layanan yang lebih baik. Dalam hal ini layanan online, mengembangkan antarmuka pengguna yang lebih baik dengan teknologi yang berbeda sangat penting, karena kemampuan antarmuka pengguna menambahkan banyak untuk menggunakan Teknologi Informasi (TI) proses adopsi. Jadi menempatkan penekanan pada pemasaran dan pengguna pelatihan yang lebih baik akan membantu adopsi layanan online.

10. Penelitian ini dilakukan oleh John R. Olson dari University of St Thomas, Minneapolis, Minnesota, USA, pada tahun 2005 yang berjudul "Internet Ticketing In A Not-For-Profit, Service Organization: Building Customer Loyalty". Penelitian ini membahas tentang melihat cara-cara di mana internet telah mengubah cara di mana banyak organisasi sekarang melakukan bisnis. Internet telah membuat pemindahan informasi mudah tapi memenuhi pesanan online telah terbukti menjadi tantangan. Hasil penelitian menunjukkan bahwa pelanggan menyadari manfaat yang signifikan dari menggunakan internet untuk membeli tiket konser. Pelanggan juga menunjukkan bahwa mereka puas dengan pengalaman layanan internet mereka. Peran internet dalam organisasi akan berubah secara dramatis selama dekade berikutnya. Untuk organisasi yang mencoba untuk menggunakan internet sebagai media penjualan utama, mereka harus menyadari bahwa kesuksesan mereka bergantung pada pengembangan basis pelanggan yang berkelanjutan. Untuk organisasi yang didirikan, integrasi internet ke dalam bisnis yang ada akan menjadi salah satu kunci keberhasilan di masa depan.

Setelah melakukan tinjauan dari sepuluh literature review yang ada, telah banyak penelitian mengenai penggunaan sistem pelayanan informasi ticketing online dan media informasi secara online. Oleh karena itu penulis membahas tentang "Optimalisasi Penerapan Sistem ROOSTER Berbasis OsTicket Untuk Meningkatkan Mutu Pelayanan" untuk meningkatkan sistem pelayanan informasi pada ROOSTER yang sudah ada menjadi lebih baik lagi yang diterapkan oleh Perguruan Tinggi Raharja.

\section{PEMECAHAN MASALAH}

Dalam mengatasi permasalahan tersebut yang telah dijelaskan sebelumnya, maka diperlukan suatu perbaikan pada sistem ROOSTER tersebut yaitu salah satunya dengan cara mengupdate sistem yang digunakan ROOSTER yaitu OsTicket yang sebelumnya menggunakan versi v1.7 kemudian di update menjadi versi v1.9.12 untuk mengoptimalkan kinerja sistem yang lebih baik lagi. Dari rumusan masalah tersebut telah menghasilkan pemecahan masalah diantaranya yaitu, dengan sistem yang telah di update kedalam versi yang lebih baik tampilan full name pada saat di inputkan email operator maka email yang di 
input sesuai dengan full name yang tampil, overdue ticket yang sebelumnya tidak aktif setelah di update overdue ticket tersebut sudah kembali aktif tanpa diberikan kodingan tambahan atau secara manual, tampilan yang lebih baik lagi dari yang sebelumnya serta dalam penyampaian informasi kepada customer, PIC bisa diingatkan dengan menambahkan internal note sebagai bukti bahwa informasi yang telah PIC berikan kepada operator untuk disampaikan kembali kepada customer telah dilengkapi tools untuk menambahkan gambar bisa berupa bukti print screen bahwa jawaban tiket ROOSTER memang sudah disampaikan pada saat PIC menjawab tiket tersebut sehingga informasi bisa diterima dengan tepat waktu sesuai pelayanan yang ditentukan yaitu $2 \times 24$ jam pada jam kerja (Senin s/d Jumat). Pada pemecahan masalah menggunakan mind mapping.

\section{Mind Mapping}

Mind Mapping merupakan metode mencatat secara menyeluruh dalam satu halaman. Mind Mapping menggunakan pengingat-pengingat visual dan sensorik dalam suatu pola dari ide-ide yang berkaitan. Peta pikiran atau Mind Mapping pada dasarnya menggunakan citra visual dan prasarana grafis lainnya untuk membentuk kesan pada otak ([Menurut Porter \& Hernacki, 2008]).

Mind Mapping juga merupakan suatu cara penyampaian informasi dengan tampilan yang lebih mudah dipahami serta lebih simple karena menuju ke bagian-bagian yang penting saja atau kepada intinya secara langsung dalam suatu tulisan dan tampilan yang bisa disesuaikan serta tidak terlihat monoton. Mind Mapping menjadi salah satu penerapan praktis dalam proses pembelajaran, penulisan serta pengembangan diri karena dalam penerapannya dengan cara hasil menggunakan otak kanan dan kirinya secara simultan.

Pada metode mind mapping ini menghasilkan sebagai berikut yaitu penjelasan mengenai Sistem ROOSTER yang ada pada Perguruan Tinggi Raharja, yaitu penjelasan apa itu ROOSTER, merupakan sebuah pelayanan informasi didalam iDuHelp! yang fungsinya menjawab pertanyaan-pertanyaan yang tidak terdapat di $i R a$ atau hanya PIC saja yang dapat mengeksekusi atau mengetahui jawaban tersebut. ROOSTER merupakan sebuah tiket online yang ditujukan kepada PIC terkait dengan waktu penanganan $2 \times 24$ jam.

Tujuan ROOSTER untuk memberikan kemudahan kepada Pribadi Raharja dalam mendapatkan informasi seputar TPi/FiR yang harus dieksekusi, mengetahui seberapa penting sebuah sistem informasi yang ada saat ini terlihat dari berapa banyak tiket ROOSTER yang masuk, dan mengetahui tingkat keakuratan sebuah informasi yang disampaikan serta menyajikan sebuah sarana yang bersifat online. Kelebihan ROOSTER yaitu operator/staff ROOSTER dapat melakukan proses ticketing secara online, informasi yang diterima sangat terpercaya karena dari sumbernya langsung yaitu PIC terkait, dan informasi dapat tersampaikan dengan tepat waktu sesuai dengan prosedur yang ada yaitu 2x24 jam. Kekurangan yang ada pada ROOSTER yaitu masih adanya operator yang suka lalai dalam melemparkan informasi yang telah dijawab dalam tiket ROOSTER kepada customer yang bersangkutan. 


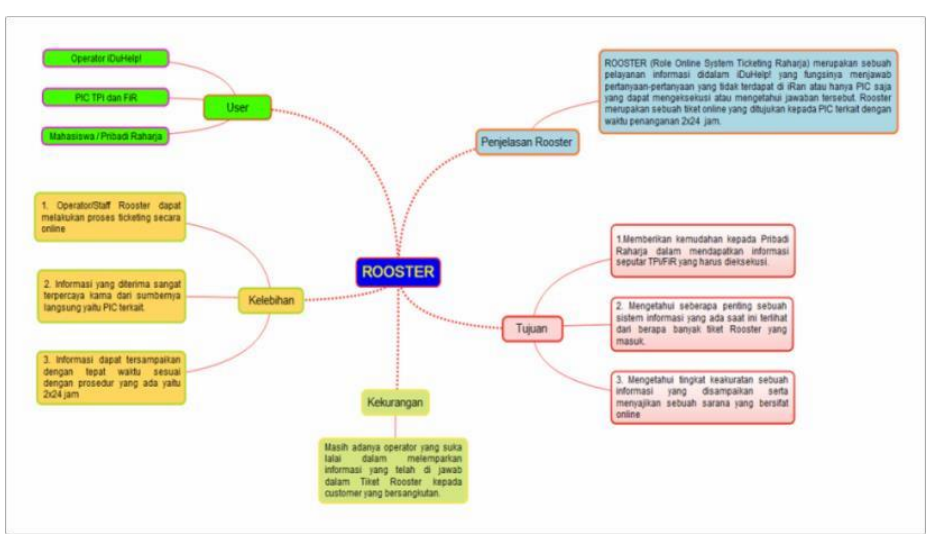

Gambar 4. Mind Mapping ROOSTER

\section{Strategi}

Strategi adalah proses manajerial untuk mengembangkan dan menjaga keserasian antara tujuan perusahaan, sumber daya perusahaan, dan peluang pasar yang terus berubah, dengan tujuan untuk membentuk dan menyesuaikan usaha perusahaan dan produk yang dihasilkan sehingga bisa mencapai keuntungan dan tingkat pertumbuhan yang menguntungkan ${ }^{([\text {Menurut Kotler 2008:25]). }}$

Langkah-langkah yang tertuang didalam strategi project yang merupakan sebuah proses pencapaian guna meningkatkan sistem ROOSTER agar menjadi lebih optimal serta lebih baik lagi untuk digunakan oleh staff ROOSTER khususnya sebagai pengguna aktif ROOSTER itu sendiri, dan eliminasi dari hasil elisitasi maka terciptalah 15 strategi seperti yang ada pada gambar dibawah ini :

Tabel 1. Eliminasi dari hasil elisitasi mendapatkan 15 Strategi ROOSTER

\begin{tabular}{|c|l|c|}
\hline No & \multicolumn{1}{|c|}{ Strategy } & Status \\
\hline 1 & Membuat 1 logo baru ROOSTER beserta filosofinya & $\checkmark$ \\
\hline 2 & Menampilkan 1 menu overdue ticket pada ROOSTER & $\checkmark$ \\
\hline 3 & $\begin{array}{l}\text { Menampilkan Full Name yang akurat pada ROOSTER dengan target } \\
\text { berhasil dibuktikan oleh 20 staff ROOSTER }\end{array}$ & $\checkmark$ \\
\hline 4 & Membuat 10 artikel tentang ROOSTER di iRan & $\checkmark$ \\
\hline 5 & $\begin{array}{l}\text { Membuat 6 template jawaban tiket ROOSTER pada canned response } \\
\text { email iDuHelp! }\end{array}$ & $\checkmark$ \\
\hline 6 & Mendapatkan tiket ROOSTER dengan target 100 tiket masuk & $\checkmark$ \\
\hline 7 & $\begin{array}{l}\text { Mengupdate sistem ROOSTER lamake sistem ROOSTER baru dari versi } \\
\text { v1.7 ke versi v1.9.12 }\end{array}$ & $\checkmark$ \\
\hline 8 & Memiliki 100 Staff ROOSTER & $\checkmark$ \\
\hline 9 & Terdapat insert image pada form new ticket & $\checkmark$ \\
\hline 10 & $\begin{array}{l}\text { Terdapat menu untuk custom logopada sistem ROOSTER tanpa hanus } \\
\text { melakukan codingan manual }\end{array}$ & $\checkmark$ \\
\hline 11 & $\begin{array}{l}\text { Terdapat notifikasi yang diterima PIC pada saat menerima tiket dan tiket } \\
\text { yang terjawab }\end{array}$ & $\checkmark$ \\
\hline 12 & $\begin{array}{l}\text { Terdapat menu user pada sistem baru ROOSTER untuk melihat aktivitas } \\
\text { user directory }\end{array}$ & $\checkmark$ \\
\hline 13 & Memiliki Lookup or create a user & $\checkmark$ \\
\hline 14 & Pada nama yang ada di Assign to bisa di urutkan berdasarkan first, last & $\checkmark$ \\
\hline 15 & Menampilkan tugas PIC pada nama staff yang ada pada Assign to & $\checkmark$ \\
\hline
\end{tabular}

\section{Flowchart Rancangan Aplikasi}

Flowchart adalah penggambaran secara grafik dari langkah-langkah dan urut-urutan prosedur dari suatu program (Menurut Adelia 2011:116]). Flowchart program biasanya digunakan dalam sebuah pemecahan masalah karena lebih mudah dibaca alurnya dari setiap langkahlangkah yang digambarkan dan dijelaskan dari awal sampai akhir yang terjadi pada sistem 
tersebut. Berikut dibawah ini merupakan flowchart yang ada pada sistem ROOSTER yang berjalan pada Perguruan Tinggi Raharja saat ini.

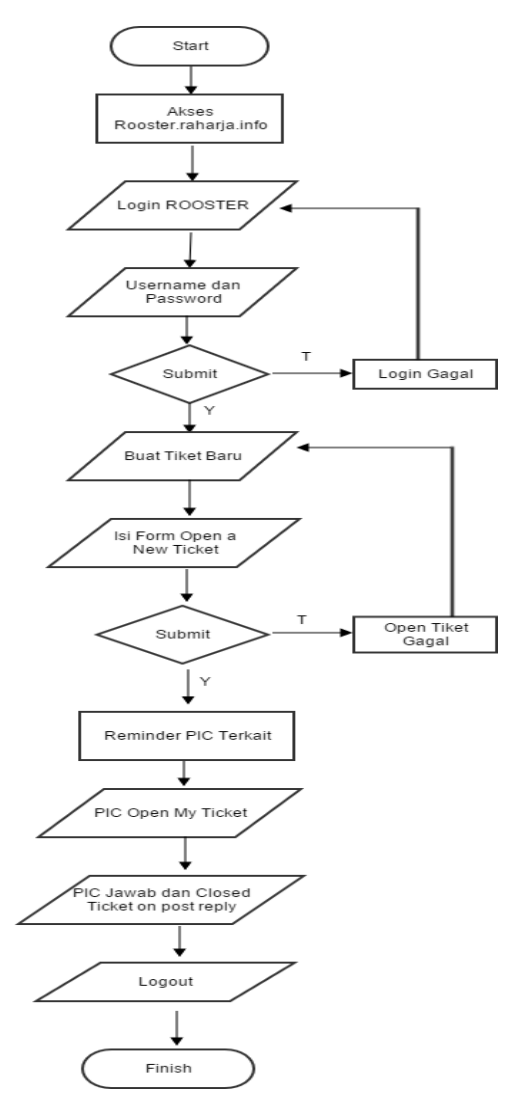

\section{Gambar 5. Flowchart Alur Sistem Pada ROOSTER Yang Berjalan di Perguruan Tinggi Raharja}

Dari gambar di atas dapat dijabarkan bahwa alur sistem yang berjalan adalah sebagai berikut, hal pertama yang harus dilakukan oleh operator iDuHelp! yaitu mengakses alamat ROOSTER terlebih dahulu yaitu Rooster.raharja.info, kemudian login dengan menggunakan account staff ROOSTER masing-masing dengan memasukkan username dan password ROOSTER, jika login berhasil dilakukan maka operator harus segera membuatkan tiket yang ada pada menu new ticket dan mengisi form open a new ticket dengan benar dan memasukkan assign to kepada PIC yang tepat, setelah berhasil maka operator wajib reminder PIC terkait melalui email kirim ke milis operator iDuHelp!, setelah operator sudah reminder PIC terkait maka yang dilakukan adalah PIC membuka tiketnya dan melakukan reply pada tiket tersebut dan ubah status dari open menjadi closed. Tahap demi tahap harus dilakukan secara benar dan tepat.

\section{Listing Program}

Di bawah ini adalah kodingan css yang dipakai dalam merancang sistem ROOSTER (Role Online System Ticketing Raharja). Berikut merupakan kodingan dalam merancang tampilan login yang ada pada sistem ROOSTER yang berjalan saat ini : 


\begin{tabular}{|c|c|}
\hline $\begin{array}{l}\text { body \{ } \\
\text { background:\#eee; } \\
\text { font-family:arial, helvetica, sans- } \\
\text { serif; } \\
\text { font-size:10pt; } \\
\text { color:\#000; } \\
\text { margin:0; } \\
\text { padding:0; } \\
\text { \} } \\
\text { a \{ } \\
\text { color:\#184E81; } \\
\text { text-decoration:none; } \\
\text { display: inline-block; } \\
\text { \}a:hover \{ } \\
\text { text-decoration: underline; } \\
\text { \} } \\
\text { \#nav a:hover, } \\
\text { \#sub_nav a:hover, } \\
\text { a:hover i[class^="icon-"], } \\
\text {.tabs a \{ } \\
\text { text-decoration: none; } \\
\text { \} } \\
\text { div\#header a \{ } \\
\text { color:\#E65524; } \\
\text { \} form_table a:hover \{ } \\
\text { text-decoration: underline; } \\
\text { \} full-width \{ } \\
\text { width: } 100 \% ; \\
\text { textered \{ } \\
\text { \} }\end{array}$ & $\begin{array}{l}\text {.search-input \{ } \\
\text { height: 20px; } \\
\text {.clear \{ } \\
\text { clear:both; } \\
\text { \} } \\
\text {.faded \{ } \\
\text { color:\#666; } \\
\text { \} } \\
\text {.strike \{ text-decoration:line- } \\
\text { through; color:red; \} } \\
\text {.canned_attachments label, } \\
\text {.canned_attachments span .uploads } \\
\text { label \{ padding:3px; padding- } \\
\text { right:10px; \} } \\
\text {.canned_attachments label \{ } \\
\text { padding-right:3px; \} } \\
\text { \#breadcrumbs \{ } \\
\text { color: \#333; } \\
\text { margin-bottom: 15px; } \\
\text { \} \#breadcrumbs a \{ } \\
\text { color: \#555; } \\
\text { \} \#msg_info, } \\
\text {.info-banner \{ margin: 0; padding: } \\
\text { 5px; margin-bottom: 10px; color: } \\
\text { \#3a87ad; border: 1px solid \#bce8f1; } \\
\text { background-color: \#d9edf7; \} } \\
\text { \#msg_notice, } \\
\text {.notice-banner \{ margin: 0; } \\
\text { padding: 5px 10px 5px 36px; } \\
\text { margin-bottom: 10px; border: 1px } \\
\text { solid \#0a0; background: } \\
\text { url('../images/icons/ok.png') 10px } \\
\text { 50\% no-repeat \#e0ffe0; \} }\end{array}$ \\
\hline
\end{tabular}

\section{IMPLEMENTASI}

ROOSTER (Role Online System Ticketing Raharja) telah di implementasikan pada Perguruan Tinggi Raharja sebagai sarana pelayanan informasi yang ada pada bagian iDuHelp! dalam menyampaikan informasi yang tidak bisa dijawab oleh operator atau hanya admin yang terkait sajalah yang bisa mengeksekusi pertanyaan tersebut. 


\section{Tampilan Login ROOSTER}

Tampilan login user pada ROOSTER dilengkapi dengan logo ROOSTER yaitu dengan memasukkan username dan password yang diberikan admin pada saat menjadi staff ROOSTER digunakan untuk dapat masuk kedalam sistem ROOSTER untuk keperluan membuat tiket ROOSTER yang ditujukan kepada pihak terkait untuk mendapatkan informasi yang akurat.

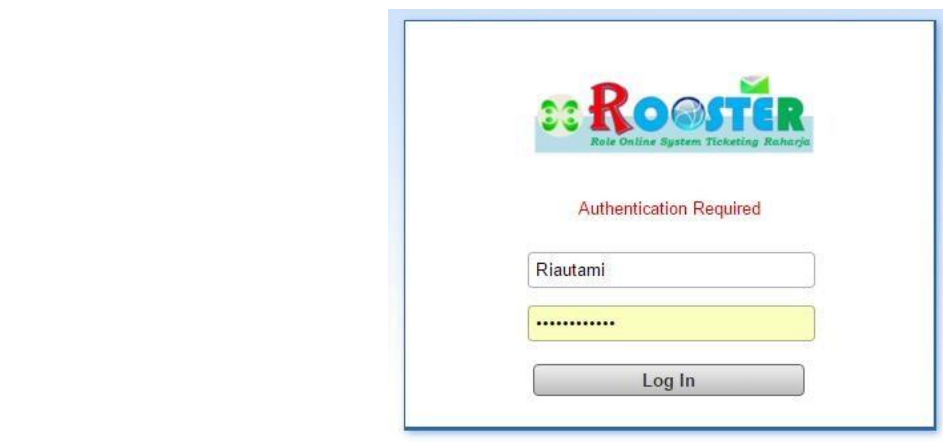

Sumber : Tampilan login pada sistem ROOSTER (rooster.raharja.info)

Gambar 6. Tampilan Login ROOSTER

\section{Tampilan menu tickets pada halaman depan ROOSTER}

Pada menu tampilan paling utama pada saat setelah login ROOSTER adalah menu tickets yang dimana berisikan tentang menu open yaitu tiket-tiket yang baru saja dibuat dan masih berstatuskan open karena belum dijawab oleh PIC yang terkait, menu overdue yaitu tiket mana saja yang telah masuk kedalam waktu overdue, artinya tiket tersebut belum ditangani oleh PIC atau PIC yang terkait belum membuka tiket tersebut dalam jangka waktu yang telah ditentukan serta peringatan untuk segera menjawab tiket tersebut dengan segera ditandai dengan tanda seru merah, terdapat menu closed artinya tiket-tiket yang sudah di closed atau telah ditangani oleh PIC yang terkait, kemudian ada menu new ticket yaitu menu untuk menuju ke form pembuatan tiket baru dan segera menjadi berstatuskan open pada menu open disertai dengan nomor tiketnya dan ada juga menu my tickets yaitu jika tiket tersebut ditujukan kepada diri kita sendiri maka akan tampil menu my tickets yang artinya harus kita buka dan selesaikan.

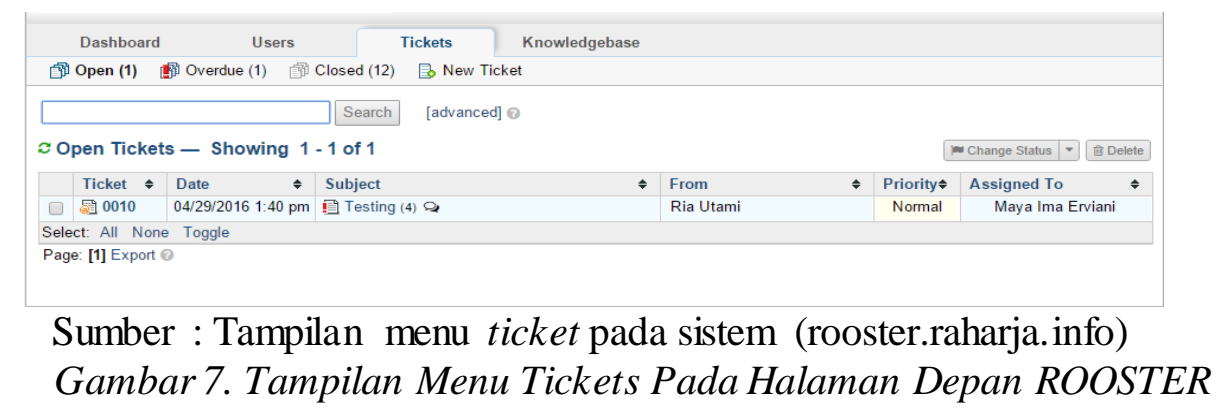

\section{Tampilan closed tickets pada menu closed}

Pada menu tickets terdapat submenu bernama closed yang berisikan tiket-tiket yang telah di jawab atau telah di closed oleh PIC terkait perihal tiket yang ditujukan kepadanya akan masuk otomatis kedalam menu closed serta terlihat siapa yang menangani atau yang closed 
tiket tersebut sehingga memudahkan informasi mengenai penanganan sebuah tiket karena dapat terlihat informasi pada tampilan menu closed berupa nomor tiket, waktu tiket tertangani atau di closed, perihal apa atau subject, siapa operatornya dan di tangani oleh siapa penanganan tiket tersebut.

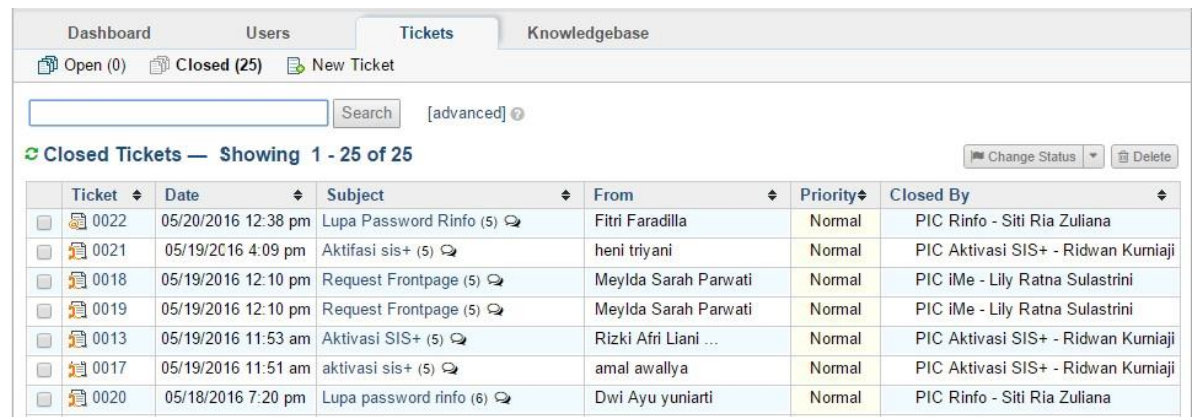

Sumber : Tampilan menu closed ticket pada sistem (rooster.raharja.info)

Gambar 8. Tampilan Menu Closed Tickets

\section{Tampilan Menu Overdue Tickets}

Overdue tickets merupakan sama halnya seperti pengingat batas waktu, misalnya pada prosedur ROOSTER itu sendiri mempunyai peraturan penanganan tiket $2 \times 24$ jam pada jam kerja yaitu senin-jumat. Maka dihari kedua overdue tiket ini bekerja untuk mengingatkan PIC terkait bahwa tiket tersebut harus segera ditangani karna mendekati waktu overdue keesokannya sehingga harus segera ditangani saat itu juga untuk memaksimalkan penyampaian informasi yang lebih cepat dan tepat waktu dan tidak membuat customer lama menunggu, dengan adanya overdue tiket ini diharapkan informasi dapat diterima dengan tepat waktu serta informasi yang diterima pun terpercaya dan akurat.

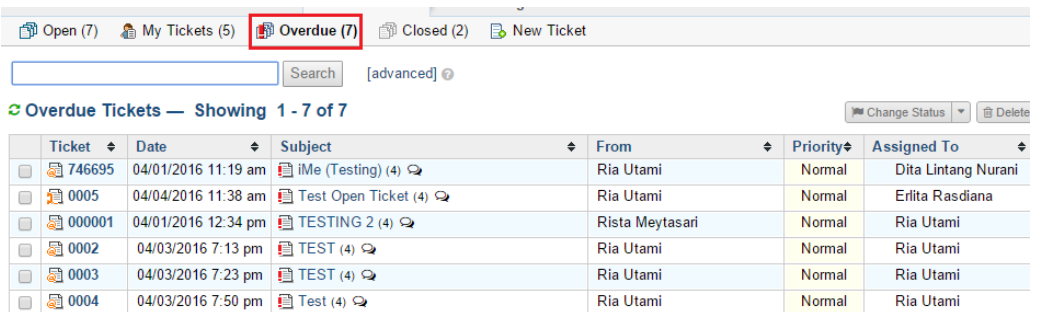

Sumber : Tampilan menu overdue pada sistem (rooster.raharja.info) Gambar 9. Tampilan Menu Overdue Tickets

\section{Tampilan Lookup or Create a User}

Tampilan Lookup or create a user muncul setiap kali membuka form new ticket pada saat operator akan membuatkan sebuah tiket dan mengisi form new ticket. Dengan adanya tampilan lockup or create a user ini berguna untuk menginputkan email rinfo dan juga full name, maka tampilan full name yang muncul akan sama seperti apa yang telah diinputkan, lookup or create a user ini juga sangat berguna untuk menghindari kekeliruan informasi full name operator pada saat membuat tiket pada versi sebelumnya. Selain itu juga dengan lookup or create user pada saat akan membuat tiket ini berfungsi sebagai kolom search account diri 
kira sendiri dan juga history untuk munculnya email serta full name kita pada form new ticket bagian email address dan full name.

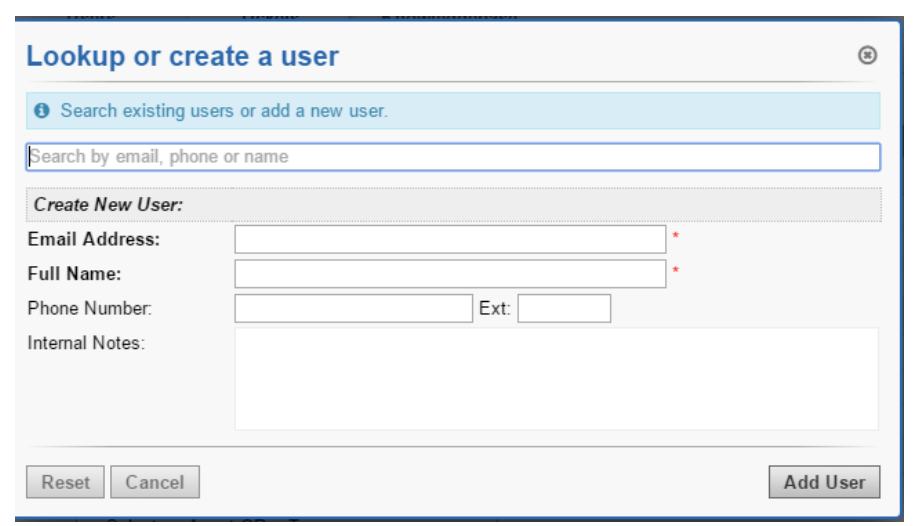

Sumber : Tampilan lookup or create a user pada sistem (rooster.raharja.info) Gambar 10. Tampilan Lookup or Create a User

\section{KELEBIHAN}

Sistem ROOSTER yang menggunakan OsTicket versi v1.9.12 overdue ticket dapat berjalan tanpa dilakukannya sebuah coding tambahan, yang berfungsi untuk memberikan peringatan kepada PIC bahwa tiket ditangani diluar prosedur atau waktu yang sudah ditentukan dalam prosedur penanganan Tiket ROOSTER yaitu 2x24 jam, maka jika melebihi $2 \times 24$ jam akan ada peringatan overdue yaitu tiket harus segera diselesaikan. Untuk tampilan full name pada saat pembuatan tiketpun dilengkapi dengan tampilan look up create a user, yaitu pengguna atau operator maupun PIC bisa mengatur full name nya sendiri tanpa harus dibenahi oleh admin. Tampilan form pun jauh lebih baik dengan dilengkapi alat pendukung dan bisa menyisipkan gambar. Hal ini membuat pengguna atau staff ROOSTER merasa lebih nyaman dari sistem sebelumnya, kesesuaian data, dan ketepatan waktu dalam penyampaian informasi kepada customer iDuHelp!.

\section{KELEMAHAN}

Tidak adanya settingan bahasa yang diinginkan sehingga bahasa yang digunakan hanyalah english. Sehingga pengguna terkadang sulit mengartikan dari tampilan menu yang masih sulit dipahami dan gambar atau logo yang digunakan tampil dengan ukuran tertentu yaitu 817x170 pixel yaitu berbentuk persegi panjang, jika tidak sesuai maka pergantian logo pada sistem akan ditolak otomatis. Segala sesuatu yang telah dioptimalkan dari segi sistem namun tetap manusia yang mengendalikan dengan ingatan manusia yang terbatas dan seringnya melakukan kesalahan dibawah prosedur yang telah ditentukan, hal tersebut tidak bisa dihindari karna ROOSTER hanyalah sebuah wadah yang disediakan untuk membantu sistem pelayanan dalam hal informasi seputar TPi.

\section{KESIMPULAN}

Dari yang telah dijelaskan diatas, maka dapat disimpulkan bahwa, penelitian ini menggunakan metode mind mapping. Penggunaan pada sistem ROOSTER dengan OsTicket 
terbaru yaitu versi v1.9.12 dinilai jauh lebih baik dari versi sebelumnya dari segi penggunaan, karena pada versi terbaru ini penggunaan ROOSTER dapat lebih optimal dan dapat bekerja lebih baik sehingga nyaman digunakan oleh operator maupun PIC yang ada. Hal ini dibuktikan dengan permasalahan yang terjadi serta dengan pemecahan masalah yang telah dijabarkan bahwa dengan dilakukannya update sistem tersebut mampu mengubah permasalahan pada ketidakakuratan data pada form new ticket dan tampilan awal yaitu informasi pada subject from yang tidak sesuai dengan data yang sebenarnya. Sistem baru telah dilengkapi alat pendukung yang cukup baik dalam penyampaian informasi yang akurat seperti dilengkapinya tambah gambar pada post internal note, dilengkapi dengan setting untuk memilih logo sesuai keinginan kita tanpa melakukan codingan manual, serta penyampaian informasi lebih tepat waktu dengan adanya overdue ticket yang muncul pada saat waktu due nya telah melewati batas sehingga penyampaian informasi jauh lebih terarah dengan waktu yang telah ditentukan sesuai prosedur yang ada, tidak ada customer yang terabaikan. Diharapkan dengan adanya perbaikan pada sistem ROOSTER ini, wadah penyampaian informasi yang akurat kepada Pribadi Raharja menjadi jauh lebih baik dan meningkatkan kenyamanan para customer yaitu seluruh Pribadi Raharja dalam menerima informasi penting yang berkaitan dengan akun TPi atau FiR yang dimiliki.

\section{DAFTAR PUSTAKA}

[1] Kotler. 2002. "Manajemen Pemasaran di Indonesia : Analisis, Perencanaan, Implementasi dan Pengendalian". Jakarta: Salemba Empat.

[2] Kotler, Philip. 2013. “Marketing Management, $11^{\text {th }}$ Edition”. Prentice Hall Int'l, New Jersey. p.138

[3] Hermawan. 2010. "Penelitian Bisnis”. Jakarta: Grasindo.

[4] Virnawati, Farah, Tirta Paramitta, I. Wayan S. Wicaksana. 2007. "Optimalisasi Penentuan Keputusan Ticketing Online Bagi Customer".

[5] Qteishat, Mazen Kamal, Haitham Hmoud Alshibly, Mohammad Atwah Al-ma'aitah. 2014. "The Impact Of E-Ticketing Technique On Customer Satisfaction: An Empirical Analysis". JISTEM-Journal of Information Systems and Technology Management. Vol 11, No 3. ISSN : 1807-1775

[6] Sunarya, Abas, Untung Rahardja, Ayu Wanda Lestari. 2015. "Kepuasan Pelanggan ROOSTER Atas Kinerja Pelayanan ROOSTER Pada Perguruan Tinggi Raharja”.

Vol.9 No.1. ISSN: $1978-8282$

[7] Rahardja, Untung, Nur Azizah, Santika Dewi. "Sistem Pelayanan Dukungan Role Online System Ticketing Raharja (ROOSTER) Dengan Menggunakan E-Ticket". CCIT Journal ISSN 8282 (1978).

[8] Rahardja, Untung, Meta Amalya Dewi, Siti Rahmawati. 2014. "Penggunaan Ekstention Waktu Dalam Role Online System Ticketing Raharja (ROOSTER) Sebagai Penunjang Pelayanan iDuHelp!".

[9] Septianita, Winda, Wahyu Agus Winarno, Alfi Arif. 2014. "Pengaruh Kualitas Sistem, Kualitas Informasi, Kualitas Pelayanan Rail Ticketing System (RTS) Terhadap Kepuasan Pengguna (Studi Empiris Pada PT. Kereta Api Indonesia (PERSERO) DAOP 9 JEMBER)”. e-Journal Ekonomi Bisnis dan Akuntansi, 2014, Volume 1 No 1 :53-56.

[10] Rahardja, Untung, Sunar Abdul Wahid, Nia Haryani. "Analisis Kinerja Student Information Service Menggunakan Technology Acceptance Model (TAM)". 2009. Vol 2 No 2. ISSN: 1978-8282 
[11] Sulaiman, Ainin. 2008. "E-ticketing as a New Way of Buying Tickets : Malaysian Perceptions". University of Malaya, Faculty of Business and Accountancy, Kuala Lumpur, Malaysia. Vol 17 No 2 : 149-157. ISSN : 0971-8923

[12] Porter, Hernacki. 2014. “Metode Pembelajaran Mind Mapping”. Biologi Online, blog pendidikan biologi. Diakses pada 1 Mei 2016 dari https://zaifbio.wordpress.com/2014/01/23/metode-pembelajaran- mind- mapping/.

[13] Olson, John R, Kenneth K Boyer. "Internet ticketing in a not-for-profit, service organization: building customer loyalty." International Journal of Operations \& Production Management. 2005.Vol 25 No 1 pp 74-92. ISSN : 0144-3577

[14] Adelia. 2011. "Implementasi Customer Relationship Management (CRM) Pada Sistem Reservasi Hotel berbasis Website dan Desktop". Bandung: Universitas Kristen Maranatha. Vol. 6, No. 2, September 2011:113-126

[15] Ozen Seneler, Cagla, Nuri Basoglu, Tugrul U. Daim. 2010. "An empirical analysis of the antecedents of adoption of online services: a prototype-based framework." Journal of Enterprise Information Management Vol 23 No 4 : 417-438. ISSN: 1741-0398

[16] Ariessanti, Hani Dewi, Febriyanto, Erick, Hanifah, Nida. 2014. "Pelayanan Sistem iDuHelp! (iLearning Education Help) Dengan Menggunakan Sistem iLearning Survey Pada Perguruan Tinggi". Vol.8 No.1. ISSN: 1978 - 8282.

[17] iLearning, Roadmap. iMe berjudul "10 Pillar IT iLearning". Diakses pada 16 juni 2016 dari http://roadmap.ilearning.me/10-pillar-it-ilearning/.

[18] Machmud, Rizan. 2013. "Peranan Penerapan Sistem Informasi Manajemen Terhadap Efektivitas Kerja Pegawai Lembaga Pemasyarakatan Narkotika (LAPASTIKA) Bollangi Kabupaten Gowa”. Jurnal Capacity STIE AMKOP Makassar. Vol. 9 No. 3. ISSN : 1907-3313.

[19] Anugerah, Delly Permana. 2009. "Peranan Misi Strategis Dalam Meningkatkan Pengaruh Pilihan Manajerial Terhadap Tingkat Kepentingan Kinerja Perusahaan”. Studi pada bisnis Boutiq : Yogyakarta.

[20] iLearning, Rooster. iMe. 2013. Berjudul “About ROOSTER”. Di akses pada tanggal 16 Juni 2016 dari http://rooster.ilearning.me/. 